\title{
Communication in single- and two-parent families and their influence on Portuguese and Spanish adolescents' life satisfaction
}

\author{
Inês Camacho ${ }^{a, b}$, Antonia Jiménez-Iglesias ${ }^{c}$, Francisco Rivera ${ }^{d}$, Carmen Moreno ${ }^{c}$ and \\ Margarida Gaspar de Matos (iD) a,b,e \\ ${ }^{a}$ Equipa Aventura Social/Faculdade de Motricidade Humana da Universidade de Lisboa, Lisbon, Portugal; \\ ${ }^{\mathrm{b}} \mathrm{SAMM} /$ Universidade de Lisboa, Lisbon, Portugal; 'Department of Developmental and Educational \\ Psychology, University of Seville, Sevilla, Spain; 'Department of Methodology and Behavioural Sciences, \\ University of Huelva, Huelva, Spain; ${ }^{\mathrm{e} W J C R / I S P A}$ - Instituto Superior de Psicologia Aplicada, Lisboa, Portugal
}

\begin{abstract}
Aim: The aim of this study was to analyse the influence of family type on communication with parents and family, as well as to analyse the contribution of communication in single- and twoparents families to adolescent life satisfaction in Portugal and Spain. Methodology: Participants were 5005 Portuguese and 21,423 Spanish adolescents aged 11-16 years, from the 2014 edition of the Health Behaviour in School-aged Children study in Portugal and Spain.

Results: Results showed that communication with parents and communication with family, in general, were higher in two-parent families than in single-parent families and was relevant to predict adolescent life satisfaction from single- and two-parent families in Portugal and Spain.

Conclusion: The results prove that communication with family is essential to predict life satisfaction in both countries. It is important to work on improving conditions of family life, as well as to implement programmes that promote better communication between all family members, especially in single-parent families.
\end{abstract}

\section{ARTICLE HISTORY}

Received 10 July 2016

Accepted 25 July 2017

\section{KEYWORDS}

Single-parent families; twoparent families; communication; life satisfaction; adolescence

\section{Introduction}

Spanish and Portuguese adolescents perceive their families as positive specifically in aspects such as good family relationships and parent-child communication (Serrano, El-Astal, \& Faro, 2004). In general, Portugal and Spain share many cultural and political similarities, making a study of this type relevant in both countries. For example, Spain and Portugal are two of the European countries that allocate fewer funds to family related policies (Instituto de Política Familiar, 2014); the education systems are similar in both countries, their adolescent population's perception about school generates concern (Inchley et al., 2016), and the model for providing school health-services in both countries is community-based (children and adolescents are supervised by health professionals working in off-site health centres) (Pommier et al., 2010). Additionally, adolescents 
from Spain and Portugal show a positive perception of their families and parental support (Serrano et al., 2004).

Communication with parents is easier for younger adolescents and communication with the mother is usually easier than communication with the father, [the latter of] which is, in general, perceived as easier by boys than by girls (Tabak et al., 2012). Parent-adolescent communication is a protective factor for adolescent life satisfaction (Boniel-Nissim et al., 2015; Karademas, Peppa, Fotiou, \& Kokkevi, 2008; Levin \& Currie, 2010), especially communication with the mother and particularly among girls (Levin \& Currie, 2010). In fact, family communication is strongly associated with adolescent well-being (Jackson, Bijstra, Oostra, \& Bosma, 1998), which is lower in girls and in older adolescents (Ramos, Moreno, Rivera, Matos, \& Morgan, 2012), and it has been shown that parental communication is more important than peer communication for psychological complaints (Moreno et al., 2009) and life satisfaction (Tomé, Matos, Camacho, Simões, \& Diniz, 2012). In addition, positive communication with parents is associated with higher life satisfaction, especially for girls. Adolescents who maintain open and sincere communication with their parents may feel parental support, trust and closeness through this communication (Cava, Buelga, \& Musitu, 2014).

The quality of communication with the mother and father is more important for life satisfaction than family structure (Levin \& Currie, 2010; Levin, Dallago, \& Currie, 2012). Additionally, the relations between life satisfaction and communication with the mother and father are similar by family structure (Levin \& Currie, 2010).

In this study, two types of families are analysed: two-parent families and single-parent families.

In Portugal (Instituto Nacional de Estatística, 2014) and Spain (Instituto Nacional de Estatística, 2014), around 14\% of families are single-parent families (14.9\% in Portugal in 2011 and $14.3 \%$ in Spain in 2013) and more than $80 \%$ of these families are singlemother families (86.7\% in Portugal in 2011 and 82.7\% in Spain in 2013). Therefore many studies about single-parent families either focus specifically on single-mother families or sample selection of their single-parent families naturally results in a high majority of single-mother families.

It has been found when compared to traditional families, single-parent families show lower scores in global assessment of family situation, have a lower income level, as well as a higher but not [statistically] significant level of conflict (Arranz, Oliva, Olabarrieta, \& Antolín, 2010). A study with single-mother families found that these families face different issues, such as economic problems, conciliation of work and family or responsibilities overload (Morgado, González, \& Jiménez, 2003). In fact, single-parent families show concern about economic problems and demand economic support, as well as tend to be concerned that their children have experienced family conflicts and thus may have a worse relationship with the other biological parent (Arranz, Oliva, Martín, \& Parra, 2010).

It seems that single-parent families have poorer communication, lower family cohesion and more conflict than two-parent families (Baer, 1999). Parent-child communication includes adolescent disclosure and parental solicitation (Keijsers, Branje, VanderValk, \& Meeus, 2010) and in this sense it has been shown that adolescents in two-parent families perceive more disclosure, parental solicitation and trust their parent-child relationship more than adolescents in single-parent families (Bumpus \& Rodgers, 2009). In addition, other study have found that child disclosure is higher in two-parent families, whereas 
parental solicitation is higher in single-parent families, probably because single-parent families do not have enough time to create situations which promote disclosure and they need more solicitation of information from the children or other sources (PadillaWalker, Harper, \& Bean, 2011).

Regarding adolescents adjustment, it has found that boys who live in single-mother families, and especially in single-father families, have lower life satisfaction, independent of family affluence (Levin \& Currie, 2010). Similarly, adolescents aged 13 and 15, who live in single-father families have lower life satisfaction than adolescents who live in other family structures (these differences are explained partially by family affluence) (Levin et al., 2012). With respect to family structure it has been shown that adolescents who live in two-parent families and single-mother families have similar levels of life satisfaction, whereas adolescents who live in single-father families, single-parent with other adults or those who live with no parents have higher risk of life dissatisfaction (Kwan, 2007). In a study by Oliva, Arranz, Parra, and Olabarrieta (2014) at least two types of single-parent families were indicated: product of a divorce and product of a woman's decision to have children alone. The last category had a better profile, although the children's internalising and externalising of problems were not higher in single-parent families after a divorce.

Nevertheless, it is important to take into account that the quality of family context depends on socio-demographic variables and other interactive variables, but does not depend on family structure (Arranz, Oliva, Olabarrieta, et al., 2010). Likewise, family structure is not related to children's adjustment however socio-demographic and contextual variables are associated (Oliva et al., 2014).

Therefore, quality of family life, but not family structure, is very important for wellbeing (Golombok, 2006). In addition, despite differences in family structure, they tend to share similar concerns and demands, such as concern for their children's health and as well as demand educational guidelines about upbringing (Arranz, Oliva, Martín, et al., 2010).

The aims of this study were to examine the influence of family type family (two-parent families, single-mother families and single-father families) on parental communication, as well as to analyse the contribution of communication in single- and two-parent families to adolescent life satisfaction after the effect of gender and age had been deleted in Spain and Portugal.

\section{Method}

\section{Participants}

Participants in this study come from the 2014 edition of the Health Behaviour in Schoolaged Children (HBSC) study, a WHO collaborative cross-national study, in Portugal and Spain. Portuguese participants were randomly chosen from 36 national vertical clusters of schools, in a total of 473 classes, in a national sample geographically stratified by Education Regional Divisions (Matos, Simões, Camacho, Reis, \& Equipa Aventura Social, 2015). Spanish participants were selected through a random multistage sampling procedure stratified by conglomerates taking into account: age, habitat (rural or urban) and type of educational centre (public or private) (Moreno et al., in press). 
In this study, the sample was composed of 26,428 Portuguese and Spanish adolescents 11-16 years old from two-parent families ( $49.75 \%$ boys, $50.25 \%$ girls and 13.58 mean age, $\mathrm{SD}=1.68)$, single-mother families $(45.22 \%$ boys, $54.78 \%$ girls and 13.84 mean age, $\mathrm{SD}=$ 1.64 ) and single-father families ( $56.28 \%$ boys, $43.72 \%$ girls and 13.85 mean age, $\mathrm{SD}=1.68$ ), as is showed in Table 1.

\section{Measures}

The measures employed in this study are taken from the 2014 edition HBSC questionnaire. Specifically, the selected variables were the following:

- Country: Portugal and Spain.

- Gender: boy and girl.

- Age: 11-12, 13-14 and 15-16 years.

- Family type: two-parent families and single-parent (single-mother and single-father) families.

- Communication with the mother and the father: these variables were developed by the HBSC study and they have been used in each data collection process since the 2002 edition of the HBSC study, 'How easy is it for you to talk to the following persons about things that really bother you?: father/ mother' (Brooks et al., 2013). Each item ranges from 1 (very difficult) to 4 (very easy).

- Communication with the family: this variable is a short version of the clear communication dimension from Family Dynamics Measure II (FDM II) (Lasky et al., 1985; White, Grzankowski, Paavilainen, Åstedt-Kurki, \& Paunonen-Ilmonen, 2003). It is composed of four items 'In my family... I think the important things are talked about/when I speak someone listens to what I say/we ask questions when we don't understand each other/when there is a misunderstanding we talk it over until it's clear'. The scale ranges from 1 (strongly agree) to 5 (strongly disagree).

- Life satisfaction: this variable was based on the Cantril Ladder (Cantril, 1965): 'Here is a picture of a ladder. The top of the ladder " 10 " is the best possible life for you and the bottom " 0 " is the worst possible life for you. In general, where on the ladder do you feel you stand at the moment?'. The item ranges from 0 (worst possible life) to 10 (best possible life).

\section{Procedure}

In Portugal, the study was approved by the Ethical Commission of the Hospital S. João do Porto and the Portuguese Ministry of Education (Matos et al., 2015). In Spain, the study

Table 1. Sample of the study.

\begin{tabular}{lrrrr}
\hline & \multicolumn{2}{c}{ Portugal } & \multicolumn{2}{c}{ Spain } \\
\cline { 2 - 3 } & $N$ & $\%$ & $N$ & $\%$ \\
\hline Two-parent families & 3751 & 74.95 & 17,330 & 80.89 \\
Single-mother families & 1118 & 22.34 & 3604 & 16.82 \\
Single-father families & 136 & 2.72 & 489 & 2.28 \\
\hline
\end{tabular}


was authorised by the University of Seville Ethical Research Committee and the Spanish Ministry of Health, Social Services and Equality (Moreno et al., in press).

Data collection was realised in both countries through an online questionnaire. The procedure adhered to international guidelines accomplished the requirements of the HBSC study (Matos et al., 2015; Moreno et al., in press): the questionnaires must be answered by the adolescents themselves; the anonymity and confidentiality of their answers must be assured; and the administration of the questionnaires must be done within the school context (Inchley et al., 2016).

\section{Data analyses}

IBM SPSS Statistics 23 programme was used for statistical analyses. All analyses were performed separately for Portugal and Spain.

Univariate ANOVAs were carried out to analyse the influence of family type (twoparent families, single-mother families and single-father families) on communication with the family (specifically $F$ significance test and Bonferroni post hoc multiple comparisons were calculated). Student $t$ tests were used to assess the influence of family type (twoparent families and single-mother families or single-father families) on communication with the mother and communication with the father. Cohen's $d$ effect size tests were calculated in both analyses when the differences were significant, considering values from 0 to 0.199 as negligible effect, small effect from 0.20 to 0.499 , medium effect values from 0.50 to 0.799 and large effect from 0.80 or greater (Cohen, 1988).

In order to control the effect of gender and age on life satisfaction, previous General Linear Models were realised, saving the unstandardised residual dependant variable. Afterwards, General Linear Models were performed in each family type to analyse the contribution of communication with both parents and communication with the family to unstandardised residual life satisfaction variable after the effect of gender and age had been deleted. First, General Linear Models were carried out to analyse the contribution of communication with one or both parents and to keep aside the unstandardised residual dependant variable. Finally, General Linear Models were performed to examine the influence of family communication on the unstandardised residual dependant variable after the effect of communication with one or both parents had been eliminated. $R^{2}$ values showed the relevance of the models, taking into account that values from 0 to .019 were negligible, from .02 to .129 were small, from .13 to .259 were medium, and from .26 or greater were large (Cohen, 1988). Partial eta squared values indicated the effect of each variable and, according to Cohen's criteria (1988), were considered as negligible (0 to .009), small (.01 to .059), medium (.06 to .149) or large (.15 or greater).

\section{Results}

Univariate ANOVAs revealed that communication with family was significantly different according to the family type in Portugal, $F(2,4993)=14.536, p<.001$, and in Spain, $F(2$, $10241)=83.079, p<.001$. The differences were significant and with small effect size among two-parent families and single-father families in both Portugal (Bonferroni test $p=.022 ; d=0.25$ ) and Spain (Bonferroni test $p<.001 ; d=0.28$ ), and among two-parent families and single-mother families in Spain (Bonferroni test $p<.001 ; d=0.33$ ). 
Communication with the family had higher values in two-parent families than in singleparent families, as shown in Table 2.

Student $t$ test did not show statistically significant differences in communication with the mother according to family type in Portugal $(t(4784)=1.263, p=.207)$. However, in Spain there were significant differences and with small effect size $(t(19282)=11.696$, $p<.001, d=0.23$ ), revealing that communication with the mother was higher in twoparent families than in single-mother families. On the contrary, student $t$ test results about communication with the father were similar in both countries, demonstrating that the family type did not influence on communication with the father neither in Portugal, $t(3822)=-1.083, p=.279$, nor in Spain, $t(16487)=0.177, p=.860$.

However, General Lineal Models used to control the effect of gender and age on life satisfaction were significant and with small effect size in Portugal $(F(3,5524)=87.999$, $\left.p<.001, R^{2}=.046\right)$ and in Spain $\left(F(3,18488)=484.230, p<.001, R^{2}=.073\right)$.

After controlling the effects of gender and age, General Lineal Models were performed in each family type to, on one hand, assess the contribution of communication with both parents to life satisfaction, and on the other hand that of communication with family to unstandardised residual life satisfaction after the effect of communication with both parents (in the case of two-parent families) or one of them (in the case of single-parent families) had been eliminated. The results showed that in general communication with parents and communication with family were relevant to predict positive adolescent life satisfaction, as shown in Tables 3-5.

Communication with the mother was more important in Portuguese two-parent families $\left(p<.001\right.$, partial $\left.\eta^{2}=.030\right)$ than communication with the father, which did not reach a noticeable effect $\left(p<.001\right.$, partial $\left.\eta^{2}=.009\right)$, whereas in Spanish two-parent families, the effects of communication with the mother $\left(p<.001\right.$, partial $\left.\eta^{2}=.021\right)$ were slightly higher than communication with the father $\left(p<.001\right.$, partial $\left.\eta^{2}=.010\right)$. In both countries, communication with the family had a higher effect size (Portugal: $p<.001$, partial $\eta^{2}=.041$; Spain: $p<.001$, partial $\eta^{2}=.050$ ) than communication with the mother and the father.

Regarding single-mother families, in Portugal, communication with the mother had a higher importance with medium effect $\left(p<.001\right.$, partial $\left.\eta^{2}=.064\right)$ than communication with the family $\left(p<.001\right.$, partial $\left.\eta^{2}=.031\right)$. In Spain, the effect of communication with the mother was somewhat higher $\left(p<.001\right.$, partial $\left.\eta^{2}=.103\right)$ than communication with the family $\left(p<.001\right.$, partial $\left.\eta^{2}=.078\right)$, and both effect sizes were medium.

Concerning single-father families, in Portugal, communication with the father had a higher effect size with medium value $\left(p=.003\right.$, partial $\left.\eta^{2}=.067\right)$ than communication

Table 2. Communication according to family type.

\begin{tabular}{|c|c|c|c|c|c|c|c|c|c|c|}
\hline & & \multicolumn{3}{|c|}{$\begin{array}{c}\text { Communication with } \\
\text { the mother }\end{array}$} & \multicolumn{3}{|c|}{$\begin{array}{c}\text { Communication with } \\
\text { the father }\end{array}$} & \multicolumn{3}{|c|}{$\begin{array}{l}\text { Communication with } \\
\text { the family }\end{array}$} \\
\hline & & $N$ & $M$ & SD & $N$ & $M$ & SD & $N$ & $M$ & SD \\
\hline \multirow[t]{3}{*}{ Portugal } & Two-parent families & 3691 & 3.31 & 0.83 & 3690 & 2.92 & 0.97 & 3746 & 4.19 & 0.77 \\
\hline & Single-mother families & 1095 & 3.27 & 0.88 & - & - & - & 1114 & 4.05 & 0.87 \\
\hline & Single-father families & - & - & - & 134 & 3.01 & 0.97 & 136 & 4.00 & 0.91 \\
\hline \multirow[t]{3}{*}{ Spain } & Two-parent families & 16200 & 3.01 & 0.84 & 16085 & 2.70 & 0.95 & 8341 & 4.14 & 0.88 \\
\hline & Single-mother families & 3084 & 2.81 & 0.95 & - & - & - & 1664 & 3.84 & 1.00 \\
\hline & Single-father families & - & - & - & 405 & 2.69 & 1.01 & 239 & 3.89 & 1.09 \\
\hline
\end{tabular}


Table 3. General Lineal Model of the communication on life satisfaction in two-parent families.

\begin{tabular}{|c|c|c|c|c|c|c|}
\hline & \multicolumn{3}{|c|}{ Portugal } & \multicolumn{3}{|c|}{ Spain } \\
\hline & $F$ & $p$ & $R^{2}$ & $F$ & $P$ & $R^{2}$ \\
\hline Corrected model & $\begin{array}{c}155.208 \\
F\end{array}$ & $\begin{array}{c}.000 \\
p\end{array}$ & $\begin{array}{c}.078 \\
\text { partial } \eta^{2}\end{array}$ & $\begin{array}{c}443.987 \\
F\end{array}$ & $\begin{array}{c}.000 \\
p\end{array}$ & $\begin{array}{c}.062 \\
\text { partial } \eta^{2}\end{array}$ \\
\hline Communication with the mother & 113.337 & .000 & .030 & 281.961 & .000 & .021 \\
\hline Communication with the father & $\begin{array}{c}31.424 \\
F\end{array}$ & $\begin{array}{c}.000 \\
p\end{array}$ & $R^{2^{.009}}$ & $\begin{array}{c}141.726 \\
F\end{array}$ & $\begin{array}{c}.000 \\
p\end{array}$ & $\begin{array}{c}.010 \\
R^{2}\end{array}$ \\
\hline Corrected model & $\begin{array}{c}154.670 \\
F\end{array}$ & $\begin{array}{c}.000 \\
p\end{array}$ & $\begin{array}{c}.041 \\
\text { partial } \eta^{2}\end{array}$ & $\begin{array}{c}350.707 \\
F\end{array}$ & $\begin{array}{c}.000 \\
p\end{array}$ & $\begin{array}{c}.050 \\
\text { partial } \eta^{2}\end{array}$ \\
\hline Communication with the family & 154.670 & .000 & .041 & 350.707 & .000 & .050 \\
\hline
\end{tabular}

Table 4. General Lineal Model of the communication on life satisfaction in single-mother families.

\begin{tabular}{lcccccccc}
\hline & \multicolumn{3}{c}{ Portugal } & & \multicolumn{3}{c}{ Spain } \\
\cline { 2 - 4 } \cline { 6 - 7 } & $F$ & $p$ & $R^{2}$ & & $F$ & $p$ & $R^{2}$ \\
\hline Corrected model & 74.641 & .000 & .064 & & 304.418 & .000 & .103 \\
Communication with the mother & $F$ & $p$ & partial $\eta^{2}$ & & $F$ & $p$ & partial $\eta^{2}$ \\
& 74.641 & .000 & .064 & & 304.418 & .000 & .103 \\
Corrected model & $F$ & $p$ & $R^{2}$ & & $F$ & $p$ & $R^{2}$ \\
& 34.710 & .000 & .031 & & 108.455 & .000 & .078 \\
Communication with the family & $F$ & $p$ & partial $\eta^{2}$ & & $F$ & $p$ & partial $\eta^{2}$ \\
& 34.710 & .000 & .031 & & 108.455 & .000 & .078 \\
\hline
\end{tabular}

Table 5. General Lineal Model of the communication on life satisfaction in single-father families.

\begin{tabular}{lcccccccc}
\hline & \multicolumn{3}{c}{ Portugal } & & \multicolumn{3}{c}{ Spain } \\
\cline { 2 - 3 } \cline { 6 - 8 } & $F$ & $p$ & $R^{2}$ & & $F$ & $p$ & $R^{2}$ \\
\hline Corrected model & 9.448 & .003 & .067 & & 27.594 & .000 & .076 \\
Communication with the father & $F$ & $p$ & partial $\eta^{2}$ & & $F$ & $p$ & partial $\eta^{2}$ \\
& 9.448 & .003 & & .067 & & 27.594 & .000 & .076 \\
Corrected model & $F$ & $p$ & $R^{2}$ & & $F$ & $p$ & $R^{2}$ \\
& 2.660 & .105 & & .020 & & 20.546 & .000 & .107 \\
Communication with the family & 2.660 & .105 & partial $\eta^{2}$ & & $F$ & $p$ & partial $\eta^{2}$ \\
& & & .020 & & 20.546 & .000 & .107 \\
\hline
\end{tabular}

with the family $\left(p=.105\right.$, partial $\left.\eta^{2}=.020\right)$, which was not significant but with small effect size, probably due to a small sample size. In Spain, the effect of communication with the father was lower $\left(p<.001\right.$, partial $\left.\eta^{2}=.076\right)$ than the communication with the family $\left(p<.001\right.$, partial $\left.\eta^{2}=.107\right)$, and both had medium effect sizes.

\section{Discussion}

The purpose of this study was to examine the influence of family type (two-parent families, single-mother families and single-father families) on communication with the parents and the family, as well as to analyse the contributions of communication in single- and twoparent families to adolescent life satisfaction (after the effect of gender and age had been deleted).

The results show that communication with family had higher values in two-parent families than in single-father families in both Portugal and Spain, and higher values than in single-mother families in Spain, as confirmed by previous studies (Baer, 1999). Regarding communication with parents, the results of this study demonstrate 
that the communication with the mother was higher in two-parent families than in single-mother families only in Spain, whereas communication with the father was similar in two-parent families and in single-father families in both countries, although mean values of communication with father were lower than mean values of communication with mother.

These results can be related to other studies conducted in Spain which confirm that single-parent families has lower scores in global assessment of family situation and lower income levels than traditional families (Arranz, Oliva, Martín, et al., 2010) and also confront different problems, like economic problems, conciliation with work (Morgado et al., 2003) and other problems such as the relationship with the biological parent (Arranz, Oliva, Martín, et al., 2010).

On the other hand, communication with parents and communication with family, in general, were relevant to predict adolescent life satisfaction in different family types in both Portugal and Spain. The results obtained go in the same direction as those reported in other studies which show that communication is a protective factor for life satisfaction (Boniel-Nissim et al., 2015; Karademas et al., 2008; Levin \& Currie, 2010) and that communication with mother and father is more important for life satisfaction than family structure (Levin \& Currie, 2010; Levin et al., 2012).

In single-mother families, communication with the mother had a higher importance than communication with the family in both Portugal and Spain, although the difference between both communications was somewhat greater in Portugal.

In single-father families, communication with the father again had a higher effect than communication with the family in Portugal (it is necessary to interpret this result with caution since communication with family was not significant but with small effect size, probably due to a small size of the sample), whereas in Spain, the effect of communication with the family was higher than communication with the father.

Along the same lines, these results have proven that in two-parent families communication with the mother was more important than communication with the father, especially in Portugal where communication with the father did not reach a noticeable effect. This may be because in Portugal, slightly more than in Spain, women are generally still responsible for the education of the children, although both parents are increasingly held accountable for the education of children. In both countries, communication with the family was more relevant than communication with the mother and the father.

Assuming that there are differences between communication with the mother or with the father, communication with the mother is usually easier than communication with the father (Tabak et al., 2012), and communication with the mother is an especially protective factor for adolescent life satisfaction (Levin \& Currie, 2010). These differences according to gender could be an important future line of investigation.

These results contribute to reflecting on concerns about the different family types in Portugal and Spain and the effects that family type could have on communication and life satisfaction. In general, the results are very similar in Portugal and Spain, probably because Portuguese and Spanish adolescent's perception about family context and life satisfaction is similar. The results obtained confirm, like other studies, that the family structure is not important; however, the quality of family life demonstrated to be very important for well-being (Golombok, 2006). In addition, regardless of family type they tend to share certain concerns and demands, given that they are concerned for their 
children's health and demand educational guidelines about upbringing (Arranz, Oliva, Martín, et al., 2010).

On the other hand, it is indispensable to indicate some limitations of this study when interpreting the results. The HBSC study is a cross-sectional study that does not allow causal relationships to be established. Others limitations include that single-parent families are heterogeneous and this heterogeneity it is not analysed in this study.

In conclusion, the results of this study showed the importance that communication has on an adolescent's life, namely on life satisfaction, according to family type. These results help to refute prejudices about single-parent families in our society, which affect both families and children, showing that single-parent families are good developmental contexts for children's well-being. Additionally, this study demonstrates the importance of investing in families and intervening with families to promote good communication between all family members, as well the necessity to take into account the different family types and their effects on communication.

\section{Disclosure statement}

No potential conflict of interest was reported by the authors.

\section{Funding}

The HBSC study in Portugal was supported by the Direção Geral da Saúde - Ministério da Saúde. The HBSC study in Spain was supported by the Ministerio de Sanidad, Servicios Sociales e Igualdad; Antonia Jiménez-Iglesias' work was supported by the V Plan Propio de Investigación of the Universidad de Sevilla 2014, under the action 'II.5B Contrato de acceso al Sistema Español de Ciencia, Tecnología e Innovación para el Desarrollo del Programa Propio de I + D + i de la Universidad de Sevilla' and by the Ministerio de Educación, Cultura y Deporte 'Programa Estatal de Promoción del Talento y su Empleabilidad en I + D + i, Subprograma Estatal de Movilidad, del Plan Estatal de Investigación Científica y Técnica y de Innovación 2013-2016" (Referencia: JC201500399).

\section{ORCID}

Margarida Gaspar de Matos (D) http://orcid.org/0000-0003-2114-2350

\section{References}

Arranz, E., Oliva, A., Martín, J. L., \& Parra, Á. (2010). Análisis de los problemas y necesidades educativas de las nuevas estructuras familiares. Intervención Psicosocial, 19(3), 243-251. doi:10.5093/ in2010v19n3a5

Arranz, E., Oliva, A., Olabarrieta, F., \& Antolín, L. (2010). Análisis comparativo de las nuevas estructuras familiares como contextos potenciadores del desarrollo psicológico infantil. Infancia y Aprendizaje, 33(4), 503-513. doi:10.1174/021037010793139653

Baer, J. (1999). The effects of family structure and SES on family processes in early adolescence. Journal of Adolescence, 22(3), 341-354. doi:10.1006/jado.1999.0226

Boniel-Nissim, M., Tabak, I., Mazur, J., Borraccino, A., Brooks, F., Gommans, R., ... Finne, E. (2015). Supportive communication with parents moderates the negative effects of electronic media use on life satisfaction during adolescence. International Journal of Public Health, 60 (2), 189-198. doi:10.1007/s00038-014-0636-9 
Brooks, F., Tabak, I., Zaborskis, A., Granado Alcón, M. C., Zemaitiene, N., de Roos, S., ... the Family Culture Group. (2013). HBSC 2013-2014 Protocol. Section 2 part 2. Scientific rationales: 2.16 Family Culture. Unpublished manuscript.

Bumpus, M. F., \& Rodgers, K. B. (2009). Parental knowledge and its sources examining the moderating roles of family structure and race. Journal of Family Issues, 30(10), 1356-1378. doi:10. 1177/0192513X09334154

Cantril, H. (1965). The pattern of human concerns. New Brunswick, NJ: Rutgers University Press.

Cava, M.-J., Buelga, S., \& Musitu, G. (2014). Parental communication and life satisfaction in adolescence. Spanish Journal of Psychology, 17(e98), 1-8. doi:10.1017/sjp.2014.107

Cohen, J. (1988). Statistical power analysis for the behavioral science. Hillsdale, NJ: Lawrence Erlbaum Associates.

Golombok, S. (2006). Modelos de familia: ¿qué es lo que de verdad cuenta? Barcelona: Graó.

Inchley, J., Currie, D., Young, T., Samdal, O., Torsheim, T., Augustson, L., ... Barkenow, V. (2016). Growing up unequal: Gender and socioeconomic differences in young people's health and wellbeing. Health behaviour in school-aged children (HBSC) study: International report from the 2013/2014 survey. Copenhagen: Health policy for children and adolescents (Report No. 7). WHO Regional Office for Europe.

Instituto de Política Familiar. (2014). Informe evolución de la familia en Europa 2014. Retrieved from: http://www.ipfe.org/EspaC3B1a/Documentos/IPF?page=2

Instituto Nacional de Estatística. (2014). Famílias em Portugal. Dia Internacional da Família 15 de maio. Retrieved from https://www.ine.pt/xportal/xmain?xpid=INE\&xpgid=ine_destaques\& DESTAQUESdest_boui $=216875336 \&$ DESTAQUESmodo=2\&xlang=pt

Jackson, S., Bijstra, J., Oostra, L., \& Bosma, H. (1998). Adolescents' perceptions of communication with parents relative to specific aspects of relationships with parents and personal development. Journal of Adolescence, 21(3), 305-322. doi:10.1006/jado.1998.0155

Karademas, E. C., Peppa, N., Fotiou, A., \& Kokkevi, A. (2008). Family, school and health in children and adolescents: Findings from the 2006 HBSC study in Greece. Journal of Health Psychology, 13 (8), 1012-1020. doi:10.1177/1359105308097965

Keijsers, L., Branje, S. J. T., VanderValk, I. E., \& Meeus, W. (2010). Reciprocal effects between parental solicitation, parental control, adolescent disclosure, and adolescent delinquency. Journal of Research on Adolescence, 20(1), 88-113. doi:10.1111/j.1532-7795.2009.00631.x

Kwan, Y.-K. (2007). Life satisfaction and family structure among adolescents in Hong Kong. Social Indicators Research, 86(1), 59-67. doi:10.1007/s11205-007-9092-8

Lasky, P., Buckwalter, K. C., Whall, A., Lederman, R., Speer, J., McLane, A., ... White, M. A. (1985). Developing an instrument for the assessment of family dynamics. Western Journal of Nursing Research, 7(1), 40-57. doi:10.1177/0092055X8500700105

Levin, K. A., \& Currie, C. (2010). Family structure, mother-child communication, father-child communication, and adolescent life satisfaction. Health Education, 110(3), 152-168. doi:10.1108/ 09654281011038831

Levin, K. A., Dallago, L., \& Currie, C. (2012). The association between adolescent life satisfaction, family structure, family affluence and gender: Differences in parent-child communication. Social Indicators Research, 106(2), 287-305. doi:10.1007/s11205-011-9804-y

Matos, M. G., Simões, C., Camacho, I., Reis, M., \& Equipa Aventura Social. (2015). A saúde dos adolescentes portugueses em tempos de recessão. Dados nacionais do estudo HBSC de 2014. Lisboa: Centro de Malária e Outras Doenças Tropicais /IHMT/UNL \& FMH/ Universidade de Lisboa.

Moreno, C., Ramos, P., Rivera, F., Jiménez-Iglesias, A., García-Moya, I., Sánchez-Queija, I., ... Morgan, A. (in press). Los adolescentes españoles: Estilos de vida, salud, ajuste psicológico y relaciones en sus contextos de desarrollo. Resultados del estudio HBSC-2014 en españa. Madrid: Ministerio de Sanidad, Servicios Sociales e Igualdad.

Moreno, C., Sánchez-Queija, I., Muñoz-Tinoco, V., Gaspar de Matos, M., Dallago, L., Ter Bogt, T., ..., the HBSC Peer Culture Focus Group. (2009). Cross-national associations between parent and peer communication and psychological complaints. International Journal of Public Health, 54(Suppl. 2), 235-242. doi:10.1007/s00038-009-5415-7 
Morgado, B., González, M. M., \& Jiménez, I. (2003). Familias monomarentales: Problemas, necesidades y recursos. Portularia, 3, 137-160.

Oliva, A., Arranz, E., Parra, Á., \& Olabarrieta, F. (2014). Family structure and child adjustment in Spain. Journal of Child and Family Studies, 23(1), 10-19. doi:10.1007/s10826-012-9681-2

Padilla-Walker, L. M., Harper, J. M., \& Bean, R. A. (2011). Pathways to parental knowledge: The role of family process and family structure. Journal of Early Adolescence, 31(4), 604-627. doi:10.1177/0272431610366246

Pommier, J., Jourdan, D., Berger, D., Vandoorne, C., Piorecka, B., Carvalho. G. S. (2010). School health promotion: Organization of services and roles of health professionals in seven European countries. European Journal of Public Health, 20(2), 182-188. doi:10.1093/eurpub/ ckp117

Ramos, P., Moreno, C., Rivera, F., Matos, M. G., \& Morgan, A. (2012). Analysis of social inequalities in health through an integrated measure of perceived and experienced health in Spanish and Portuguese adolescents. Journal of Health Psychology, 17(1), 57-67. doi:10.1177/ 1359105311406154

Serrano, G., El-Astal, S., \& Faro, F. (2004). La adolescencia en España, Palestina y Portugal: análisis comparativo. Psicothema, 16(3), 468-475.

Tabak, I., Mazur, J., Granado Alcón, M. C., Orkenyi, A., Zaborskis, A., Aasvee, K., \& Moreno, C. (2012). Examining trends in parent-child communication in Europe over 12 years. The Journal of Early Adolescence, 32(1), 26-54. doi:10.1177/0272431611419509

Tomé, G., Matos, M. G., Camacho, I., Simões, C., \& Diniz, J. A. (2012). Portuguese adolescents: The importance of parents and peer groups in positive health. The Spanish Journal of Psychology, 15 (3), 1315-1324. doi:10.5209/rev_SJOP.2012.v15.n3.39417

White, M. A., Grzankowski, J., Paavilainen, E., Åstedt-Kurki, P., \& Paunonen-Ilmonen, M. (2003). Family dynamics and child abuse and neglect in three Finnish communities. Issues in Mental Health Nursing, 24(6/7), 707-722. 